\title{
FOUCAULT E A LIBERDADE NO ESTOICISMO TARDIO
}

\author{
Ana Lúcia dos Santos e Santos ${ }^{1}$
}

Resumo: O presente artigo visa analisar, a partir do pensamento do filósofo Michel Foucault, o exercício da liberdade sob uma perspectiva ética, no âmbito do estoicismo tardio. Liberdade essa que se faz possível a partir do cuidado de si, por meio de exercícios regulares que possibilitam ao indivíduo viver a vida como arte. Com efeito, é na prática do cuidado de si, que o indivíduo se coloca como transformador do mundo e de si mesmo, o qual dá-se no encontro com o outro, longe de ser uma experiência solitária com o próprio eu, realiza-se na associação com outrem.

Palavras-chaves: liberdade, cuidado de si, exercício.

Abstract: This article aims to analyze, based on the philosopher Michel Foucault's thought, the exercise of freedom from an ethical perspective, in the context of late stoicism. This freedom is made possible by taking care of oneself, through regular exercises that enable the individual to live life as an art. Indeed, it is in the practice of self-care, that the individual places himself as a transformer of the world and of himself, which occurs in the encounter with the other, far from being a solitary experience with his own self, it takes place in association with others.

Keywords: Freedom, Self-care, Exercise.

\footnotetext{
${ }^{1}$ Licenciada em Filosofia pela Universidade Federal do Recôncavo da Bahia, com especialização em Filosofia, pela UEFS, e em Educação pela UFBA. Mestre em Filosofia pela Universidade Federal da Bahia. Doutoranda em Filosofia pela UFBA, atuando nas linhas de pesquisa ética e política. Currículo Lattes: http://lattes.cnpq.br/0730679333263624.
} 
É na esteira das problematizações foucaultianas que o presente texto propõe analisar o exercício da liberdade sobre o prisma ético do estoicismo tardio. E para compreendermos o modo como Foucault lê os estoicos, o que entende por ética, qual a relação da ética com a liberdade e, por conseguinte o entendimento do cuidado de si, comecemos pela problematização da ética e da moral, encontrada na obra História da sexualidade II, Uso dos prazeres. Incialmente, a ética pode ser entendida como componente de moralidade que diz respeito à relação que o indivíduo tem consigo mesmo. Desse modo, a moral pode ser tomada, tanto como um conjunto de valores e regras propostas ao indivíduo, quanto aos comportamentos morais, à medida que os indivíduos se adaptam ou não a esses conjuntos de valores e regras. Com isso, é possível analisar o modo como o sujeito se constitui enquanto sujeito moral, a partir de quatro aspectos, a saber: a substância ética, o modo de sujeição, o trabalho ético e por fim, a finalidade ética (telos). Nesses moldes, a substancia ética corresponde ao momento em que o indivíduo toma como domínio o juízo ético, ou seja, "o domínio dos desejos, o combate obstinado que se tem contra eles" (FOUCAULT, 1984, p. 35), enfim, o modo como o indivíduo resiste as tentações; O modo de sujeição é a maneira pela qual o indivíduo estabelece uma relação consigo, relação que pode ser de obrigações ou de regras; O trabalho ético corresponde ao trabalho que o indivíduo desenvolve sobre si mesmo, a fim de se tornar um sujeito ético; O telos é o agir do indivíduo como meta a seguir, agir eticamente.

Segundo Foucault (1984, p. 37), uma ação para ser dita moral não deve partir do princípio de um conjunto de regras e valores, nem tampouco de um ato, e sim, de uma certa relação de si, ou seja, uma constituição de si "enquanto sujeito moral”, na qual o indivíduo irá, a partir dele mesmo (objeto), definir qual posição tomar em relação "ao preceito que respeita, estabelece para si um certo modo de ser que valerá como realização moral dele mesmo", agindo, então, sobre si mesmo, se conhecendo, controlando, aperfeiçoando e se transformando.

De acordo com Davidson (1994, p. 163), esses aspectos correspondem ao primeiro modo de pensar a ética em Foucault; o segundo modo diz respeito à relação estabelecida entre subjetividade $^{2}$ e governamentalidade ${ }^{3}$. Com efeito, a prática de governo em Foucault versa

\footnotetext{
${ }^{2}$ Foucault se opõe à noção de sujeito cartesiano, aquele tido como substância, afirmando que o sujeito é uma forma, que nem sempre é idêntica a si mesma. Assim, temos dois métodos de análise, de um lado, a problematização de uma história do sujeito, modos de subjetivação; de outro, uma mudança de estilo, de objetos e de metodologia, nessa história do sujeito, ou seja, um deslocamento da questão da episteme para as práticas de si mesmo. (Cf. Castro, 2016, p. 408). Desse modo, teremos um sujeito como efeito de uma constituição, isto é, modos de subjetivação como práticas de constituição do sujeito.
} 
sobre o eixo genealógico e o eixo ético (englobados pelo o que o autor chama de governamentalidade), a saber: o governo como relação entre os sujeitos (condução de condutas) e o governo como relação consigo (o cuidado de si). Em outras palavras, o primeiro eixo trata do conjunto de ações sobre ações, que culmina num modo de conduzir os outros e o segundo trata do domínio dos próprios prazeres e desejos. Existe uma relação entre subjetividade e governamentalidade, a qual se desenvolve a partir das relações de poder, que consiste num "campo de ação com múltiplas possibilidades, porém de uma mesma natureza" (CANDIOTTO, 2010, p. 37). Assim, os "modos de objetivação" do sujeito do conhecimento e a governamentalidade estão atrelados à crítica de um sistema de poder e ao domínio de relações estratégicas entre os indivíduos e os grupos, isto é, o governo de si mesmo e governo dos outros. Efetivamente, afirma Davidson:

Nossas "tecnologias do eu", os modos como nos relacionamos conosco, contribuem para as formas como nossa subjetividade é constituída e experenciada, bem como para as formas segundo as quais governamos nosso pensamento e conduta. Nos relacionamos conosco como tipos específicos de sujeitos que governam a si mesmos de maneira particulares. Em resposta às questões "que tipos de sujeitos devemos ser?" e "como devemos governar a nós mesmos?", Foucault ofereceu sua história ética. (DAVIDSON, 1994, p. 164).

Com efeito, a governamentalidade abarca a arte de governar, que envolve "o estudo do governo de si, o governo dos outros, bem como as formas políticas de governamentalidade, e as relações entre o governo de si e o governo dos outros" (CASTRO. 2016, p. 191). De modo mais claro, é a partir da prática do governo de si e do governo dos outros, que o indivíduo desenvolve sua autonomia e, por fim, torna-se livre, e quando se é livre, governa-se a si mesmo e consequentemente os outros, isto é, "o êthos do cuidado de si é, portanto, igualmente uma arte de governar os outros" (REVEL, 2005, p. 34).

$\mathrm{Na}$ busca de entender a relação entre a subjetividade e a governamentalidade, faz-se necessário analisar o curso A Hermenêutica do sujeito (1982), no qual Foucault estuda o modo como os indivíduos se conduziam, a partir de um conjunto de práticas que tiveram importância tanto no período grego clássico quanto no estoicismo tardio. Com isso, temos dois "modelos" de condução de comportamentos, de um lado o período clássico ${ }^{4}$, versado no

3 "O processo ou antes, o resultado do processo pelo qual o Estado de Justiça da Idade Média, que nos séculos XV e XVI se tornou o Estado administrativo, viu-se pouco a pouco 'governamentalizado"' (FOUCAUTL, 2008, p. 144-145), ou seja, processos, reflexões, táticas que permitiam um "governo", uma "regulação", especificamente sobre a população.

${ }^{4}$ Foucault toma como base de analise o Alcebíades, de Platão. 
âmbito político e de outro o estoicismo tardio ${ }^{5}$, versado no âmbito individual e estético. Diante disso, o que o período grego clássico e o estoicismo tardio tomam como liberdade? Ademais, para os gregos clássicos, a liberdade significa um problema político de não escravidão de si mesmo e de seus apetites - ser soberano em relação a si mesmo e aos seus apetites - para bem governar a cidade, pois o indivíduo que controla a si mesmo, bem se governa, bem governa sua casa, e consequentemente, bem governa a cidade. Por isso, no Uso dos prazeres, Foucault analisa o modo como os gregos clássicos lidam com os prazeres e como dominam a si mesmos, exercendo soberania sobre si mesmo. Além do domínio de si com cunho estritamente político, os gregos clássicos consideram a necessidade de desenvolver o modo particular de cuidar de si para, então, tornar-se soberano em relação aos prazeres e desejos: "Ser livre em relação aos prazeres é não estar a seu serviço [...] é poder que se exerce sobre si, no poder que se exerce sobre os outros" (FOUCAULT, 1984, p. 99). Em outras palavras, o indivíduo para poder governar uma cidade, por exemplo, deve antes dessa prática, desenvolver o domínio sobre ele mesmo, governar a si mesmo - no que concerne aos prazeres e desejos, sendo que esse domínio só será possível com o conhecimento de si, para só então passar a governar.

Para Castro (2015, p. 123), alguém pode governar a si mesmo, não ser escravo de si mesmo e produzir a si mesmo e sua vida na forma de verdade. Nesse sentido, por que é preciso que o indivíduo seja ou se torne livre? Com efeito, a noção de liberdade, no período grego clássico, se apresenta no âmbito da organização e harmonia da cidade, ou seja, o indivíduo livre desenvolve o domínio de si e, por meio desse domínio, terá condições suficientes para governar os outros. Assim, a relação que o indivíduo desenvolve consigo, a partir do domínio de si, será elemento chave para que o indivíduo se relacione com o outro, pois é nessa relação consigo e com outro que encontramos explícita a noção de governo de si e dos outros, mencionada anteriormente. Deveras, é a governamentalidade que dá condições para as estratégias, ou seja, o desenvolvimento de técnicas que possibilitam o indivíduo governar a si mesmo, em sua liberdade, a partir da relação com os outros.

No estoicismo tardio, essas práticas de governo de si e governo dos outros ainda existem, entretanto, são desenvolvidas a partir de outro viés. A prática de governo de si não tem mais um cunho totalmente político, econômico e social como no período clássico, mas uma relação do indivíduo como ser racional, ou seja, faz-se necessário uma relação de si para consigo a partir de uma reflexão mediada pela razão. À vista disso, Foucault (2014a, p. 78)

${ }^{5}$ Como problematização desse período, Foucault aborda obra de Sêneca, Marco Aurélio, Musonius Rufo, Epicteto e entre outros. 
esclarece que, enquanto no período clássico o domínio de si está fundamentalmente ligado ao poder sobre os outros, ao governo dos outros, no estoicismo tardio a questão é dominar a si mesmo como ser racional. Grosso modo, no estoicismo tardio o indivíduo não necessita, para ser senhor de si, saber qual o seu papel na sociedade (política) ou na casa, mas praticar alguns exercícios (meditação, exame de consciência, etc.) que o prepare para se deixar atingir o mínimo possível pelos acontecimentos futuros e que o possibilite se certificar que controla a si mesmo.

Desse modo, temos, de um lado, temos um período clássico em que a questão do domínio de si, por meio do cuidado de si, gira em torno do status; de outro lado, temos o estoicismo tardio que possibilita abranger esse domínio para todos os indivíduos, sem restrição, isto é, trata-se do que Foucault chamou de universalização do cuidado de si. Para os estoicos, todos os indivíduos em geral são capazes de exercer a prática de si, todos podem ascender a essa prática de si, mas nem todos são capazes de ocupar-se consigo. O cuidar de si tem grande importância nos dois períodos, pois, assim como no período clássico, os estoicos também buscam desenvolver o controle e domínio de si. No entanto, a finalidade dos estoicos está pautada na busca de viver uma vida bela e boa, ou seja, uma vida que tenha como parâmetros a estética, a ética e enfatize a individualidade, desse modo, o indivíduo encontrará a felicidade e a tranquilidade, culminando no que Foucault chama de arte de viver, "uma moral greco-romana dirigida para a ética e por meio da qual se trata de fazer de sua vida uma obra de arte" (REVEL, 2005, p. 43). Importante ressaltar que não é uma ética com cunho normalizador, que tem como finalidade universalizar e normalizar a população, porque buscar viver essa vida estética-ética é um problema pessoal, e qualquer pessoa da sociedade que almeja viver uma vida bela e boa poderá praticar os exercícios, ou seja, o indivíduo que busque praticar os exercícios, desenvolverá sua autonomia e por conseguinte modificará sua vida de modo refletido e racional, essa modificação do ser consiste em viver a liberdade ética. Desse modo, no período clássico a preocupação do indivíduo gira em torno do coletivo, ou seja, o indivíduo se domina para o bem-estar e harmonia da sociedade, enquanto que no estoicismo tardio essa preocupação se volta para o indivíduo, tornando-se essencial o modo como o indivíduo se relaciona consigo mesmo. Nas palavras de Foucault:

A ética não estava relacionada a nenhum sistema social - ou pelo menos legal institucional. Por exemplo, as leis contra o comportamento sexual ilícito eram muito poucas e não muito severas [...] o que os preocupava, seu tema, era constituir um tipo de ética que era uma estética da existência (FOUCAULT, 1999, p. 42). 
Assim, na ética do estoicismo tardio não é possível encontrar normalização, ou a ideia de regras gerais para a população, uma vez que os estoicos aspiravam viver esse êthos, "a vontade de viver uma vida bonita, e deixar para outros a memória de uma existência bonita" (FOUCAULT, 1983, p. 42). Por certo, perceberemos que a liberdade é problematizada como êthos, como modo de ser do indivíduo, pois para que "essa prática da liberdade tome forma em um êthos que seja bom, belo, honroso, respeitável, memorável e que possa servir de exemplo, é preciso todo um trabalho de si sobre si mesmo" (FOUCAULT, 2014b, p.264). O cuidado de si é ético em si mesmo, no entanto, implica relações complexas com os outros, relações essas que diferem do período clássico, pois o outro no estoicismo tardio consiste num "diretor de consciência", o qual o indivíduo aprende algumas práticas, enquanto que no período clássico, o outro tem cunho estritamente político, "uma vez esse êthos da liberdade é também uma maneira de cuidar dos outros" (FOUCAULT, 2014b, p.264).

O que importa para os estoicos é o modo como se portar diante de si, o modo como se conduzir, mais do que as questões políticas e sociais. Isso ocorre, segundo Foucault (2014a, p. 402), quando a cultura grega clássica, a tekhne toû bíou (arte de viver), se inscreve no vazio deixado pela lei e pela religião, e então, a liberdade humana encontra sua obrigação não mais nessas questões sociais, e sim na arte de si mesmo, na prática de si mesmo. Assim, será possível ao indivíduo desenvolver uma ética que busca cuidar de si, que desenvolva esse viver livre, pois na arte da vida, encontramos o desenvolvimento de uma ética que busca ocupar-se consigo, que busca ser livre, visto que o domínio perfeito sobre si tem papel central na arte de viver ${ }^{6}$.

À vista disso, no processo de estetização, no qual o indivíduo procura libertar-se dos vícios que está atrelado à prática diária, surge à noção de salvação ${ }^{7}$, pois ser livre implica salvar-se desses vícios, e das "perturbações" exteriores que de alguma forma afetam o indivíduo. Segundo Foucault (2014a, p. 166), essa salvação, que tem como operador o próprio indivíduo, não pode ser entendida apenas no sentido negativo de escapar a um perigo, é mais, se manter em um estado de alerta, de "resistência, de domínio e soberania sobre si". Assim, o indivíduo que consegue salvar a si mesmo, escapa da dominação, da escravidão de si mesmo e

\footnotetext{
${ }^{6}$ Pois nessa "arte da vida a noção de exercer domínio perfeito sobre si mesmo, logo se tornou o problema principal” (FOUCAULT, 1999, p. 48).

${ }^{7}$ Este é um momento interessante da análise de Foucault, qual mostra, ao contrário do que se supõe comumente, a "salvação" era uma meta das práticas antigas bem antes do cristianismo, ainda que pensada de modo bem distinto em relação a ele.
} 
dos outros, possibilitando-lhe "escapar a uma coerção pela qual se está ameaçado, e ser restabelecido nos seus direitos, recobrar a liberdade" (FOUCAULT, 2014a, p. 166).

De acordo com o Foucault (2014a, p. 167), salvar a si tem como finalidade tornar o indivíduo inacessível aos infortúnios e perturbações, advindas de acidentes e acontecimentos exteriores. O indivíduo atinge esse objetivo através da ataraxia e da autárkeia, isto é, a ausência de perturbações e a autossuficiência. Afirma Foucault:

A salvação é uma atividade permanente do sujeito sobre si mesmo, que encontra sua recompensa em uma certa relação consigo, ao tornar-se inacessível às perturbações exteriores e ao encontrar em si mesmo uma satisfação que de nada mais necessite senão dele próprio (FOUCAULT, 2014a, p. 167).

Nesse ínterim, o indivíduo é agente, objeto, instrumento e finalidade numa mesma atividade, bastando-se a si mesmo. Visto que, ser livre, para os estoicos, é salvar-se a si mesmo, é fugir da servidão a si mesmo, pois a servidão “é uma espécie de obrigaçãoendividamento de si e para consigo" (FOUCAULT, 2014a, p. 245).

Segundo Davidson (1994, p. 165), a noção de estética da existência encontra seu apogeu na obra $O$ Cuidado de si, no capítulo denominado "A cultura de si", no entanto, percebemos que já no curso A Hermenêutica do sujeito Foucault desenvolve o viver a vida como arte, insistindo na atenção que o indivíduo deve ter para consigo mesmo. Importante ressaltar que essa atenção não é interpretada como código de proibições e regras, e sim como uma intensificação da relação consigo, levando o indivíduo a se constituir como sujeito de seus atos, como um sujeito que dá vida a seu pensamento. Esclarece Foucault:

Essa majoração [evitar os prazeres por meio de um regime austero] da austeridade sexual na reflexão moral não toma a forma de um estreitamento do código que define os atos proibidos, mas a de uma intensificação da relação consigo pela qual o sujeito se constitui enquanto sujeito de seus atos (FOUCAULT, 2014a, p. 53).

Nesse percurso de argumentação, é necessário prestar a atenção no "para consigo" a partir da conversão para si (epistrophé eis heuton), que exige que o indivíduo modifique "suas atividades e desloque sua atenção de modo a cuidar constantemente de si mesmo" (DAVIDSON, 1994, p. 166). Ao modificar suas atividades, o indivíduo modifica seu olhar, isto é, volta o olhar para si que "constitui o termo de conversão e o objeto final de todas as práticas de si, diz respeito a uma ética do domínio" (FOUCAULT, 2014a, p. 83-85), ou seja, momento no qual o indivíduo passa a desenvolver o cuidar e dominar a si mesmo em relação aos prazeres e desejos. No entanto, esse voltar a si mesmo depende da relação com o outro, 
com mestre, que o auxiliará na tomada de consciência, e consequentemente, no prestar atenção a si mesmo.

A partir das leituras dos textos foucaultianos, perceberemos que não é de um indivíduo isolado da sociedade e que só se preocupa consigo, que se trata. Com efeito, o que Foucault (2014a, p. 85) vislumbra e analisa nos estoicos é o desenvolvimento do cuidar de si, que possibilitará ao indivíduo conhecer a si mesmo, para então, lidar com o outro, e, por conseguinte, com a sociedade. Então, o converter-se a si possibilita ao indivíduo o afastamento das preocupações e inquietações exteriores, a fim de estabelecer uma relação consigo em que nada o perturbe, ou seja, uma experiência de si que se forma na posse de si, uma experiência "que se tem consigo mesmo [...] alguém que conseguiu ter acesso a si próprio é, para si, um objeto de prazer”. Nessas condições, a conversão paralela ao cuidado de si, permite ao indivíduo desenvolver um movimento de interiorização que busque "ser mestre de si, possuir a si mesmo, encontrar sua felicidade na liberdade e na independência interior" (DAVIDSON, 1994, p. 167). E ao tornar-se mestre de si mesmo o indivíduo passa a viver uma vida bela, uma vida como obra, denominada de arte de viver. Nas palavras do filósofo francês:

\begin{abstract}
A arte da existência como práticas reflexivas através das quais os homens, não somente fixam regras de condutas, como também procuram se transformar, modificar-se em seu ser singular e fazer de sua vida uma obra que seja portadora de certos valores estéticos e responda a certos critérios de estilo (FOUCAULT, 1984, p. 17-18).
\end{abstract}

De tal modo, é a partir da arte de viver/existência por meio das "técnicas de si" que o indivíduo, possivelmente, se auto modificará. Ao escavar o eixo da relação consigo, a arte de viver, no estoicismo tardio, e o modo como indivíduo dá forma à sua subjetividade, Foucault traça o caminho de uma ética como exercício de liberdade, visto que essa ética é autoformadora e possibilita a modificação do ser, levando o indivíduo a dar forma à sua liberdade. Afirma Foucault:

A constituição de si enquanto "sujeito moral", na qual o indivíduo circunscreve a parte [o local] dele mesmo que constitui o objeto dessa prática moral, define sua posição em relação ao preceito que respeita, estabelece para si um certo modo de ser que valerá como realização moral dele mesmo; e, para tal, age sobre si mesmo, procura conhecer-se, controlase, põe-se à prova, aperfeiçoa-se, transforma-se (FOUCAULT, 1984, p. 37).

É pensando uma ética de modo particular que Foucault (1984, p. 37) diverge da noção de uma ética com princípios universalmente aplicáveis, com padrões normativos, uma vez 
que, de acordo com filósofo francês, buscar uma moralidade a qual todos devam seguir é catastrófica. Desse modo, interessa a Foucault analisar a ética, mas com o pretexto de entender a inadequação da identidade moral moderna, a qual se opõe a essa noção de ética acima citada, ou seja, uma ética que possibilite a modificação do ser a partir de uma relação consigo, de uma relação sobre si mesmo, que possibilite o controle e o conhecimento de si, que possibilite a criação de formas outras de subjetividades. Segundo Mahon e Bernauer (2016) essas práticas (do controle e conhecimento de si) são possíveis a partir de questões que possibilitaram pensar uma liberdade ética:

Como os indivíduos foram convidados ou incitados a aplicar técnicas a si mesmos que lhes permitissem reconhecer-se como sujeitos éticos? Qual o aspecto de si ou de seu comportamento é relevante para a atenção e para o juízo éticos (substância ética)? A qual regra de conduta as pessoas se sujeitam, e como elas estabelecem sua relação com essa regra (modo de sujeição)? Em que tipo de atividades as pessoas se envolvem a fim de formar a si mesmas, moderar seu comportamento, decifrar aquilo que são, erradicar seus desejos (a ascese)? Que tipo de ser alguém está tentando tornar-se por meio dessas práticas ascéticas (o telos)? (BERNAUER; MAHON, 2016, p. 193).

Desse modo, Foucault busca desenvolver uma ética, não nos padrões de normatividade aplicável a todos, mas um estilo particular, um êthos, que surge na maneira de se relacionar consigo mesmo para se construir, para se elaborar. É esse estilo particular que Foucault vislumbra nos estoicos, que possibilita o domínio e controle de si. Nesses moldes, quais são os exercícios a serem praticados, no estoicismo, que possibilitem o exercício da liberdade?

O indivíduo se torna livre com o desenvolvimento de três procedimentos, denominados por Foucault (2016, p. 31-32) de modificações do ser, ou domínios da genealogia, a saber: uma ontologia ${ }^{8}$ no que diz respeito ao desenvolvimento da relação com o outro (aprender a arte de viver), pela máthesis - artes que são aprendidas através do ensino, por meio de uma escuta; uma ontologia da verdade (interiorização do aprendizado), pela mélete - interiorização do que foi aprendido, "não há arte de viver sem a necessidade de uma retomada periódica do ensino recebido do mestre"; e, uma ontologia com relação a si, constituindo um sujeito do conhecimento, que implica uma ascese (uma série de exercícios, pela áskesis) - tentativas de fazer determinada coisa, exame de si, exame dos erros, isso tudo a partir de uma série de provas.

\footnotetext{
${ }^{8}$ Foucault denominará ontologia do presente o gesto de interrogar-se sobre a atualidade, identificando nela a existência de dispositivos de subjetivação, possibilitando a emergência de novos modos de relação do sujeito consigo e com os outros. Desse modo, podemos pensar uma ontologia que ajude o indivíduo a viver uma vida bela. Cf. FOUCAULT. Subjetividade e verdade. 2016.
} 
Grosso modo, “ensino (máthesis), relação com o outro; meditação (mélete), relação com a verdade; exercício (áskesis), trabalho de si sobre si, relação de si consigo" (FOUCAULT, 2016, p. 32-33), é o que encontraremos como forma de conduta, como formas ético-estética, nos séculos I e II de nossa era. Por certo, examinaremos esses procedimentos a seguir.

As análises de Foucault a respeito da sexualidade, a partir de 1981 (curso Subjetividade e Verdade), estão centralizadas nas técnicas de si. Segundo Frédéric Gros (2016, p. 276), essa análise da sexualidade não se resume diretamente ao governo dos homens, e sim a uma relação que o indivíduo desenvolve consigo, isto é, as técnicas de si permitem a Foucault problematizar um sujeito que constrói uma relação definida consigo, através de exercícios regulares. As práticas de si, no âmbito moral, derivam de códigos e comportamentos, os quais nos levam a pensar uma história de comportamentos que faz com que os indivíduos busquem constituir-se como indivíduos éticos. Desse modo, com o cuidado de si, esses indivíduos constituem um modo de liberdade singular pensada como ética. Foucault (FOUCAULT, 2014b, p. 262) afirma que, na cultura estoica, os indivíduos conduziam-se bem quando se adequavam a esse exercício da liberdade, ou seja, quando o indivíduo passava a ocupar-se consigo, a cuidar de si e consequentemente a conhecer a si próprio, possibilitando um êthos, uma atitude que comporte o "cuida-te de ti mesmo".

De tal modo, as técnicas de si são meios indispensáveis para o alcance da arte de viver, visto que a arte de viver é uma técnica que, por meio da relação com o outro, e no fim das contas consigo mesmo, sobre si mesmo, tenta adquirir uma determinada qualidade do ser bela e boa. São relações que possibilitam ao indivíduo modificar a experiência que tem de si mesmo, "remetendo-se a um ensinamento verdadeiro, a uma fala verdadeira, a descoberta ou busca de uma determinada verdade" (FOUCAULT, 2016, p. 34). Essa qualidade não pode ser feita sem uma ação de si sobre si, sem uma relação com o outro, tampouco, sem uma relação com verdade. Afirma Foucault:

[as técnicas de si] permitem ao indivíduo [estoico] efetuar, sozinho ou com a ajuda de outro, certo número de operações sobre seu corpo e sua alma, seus pensamentos, suas condutas, seu modo de ser; transformar-se a fim de atingir certo estado de felicidade, de pureza, de sabedoria, de perfeição e de imortalidade (FOUCAULT, 2014c, p. 226). 
Com efeito, quando o indivíduo passa a cuidar de si, deve ter como finalidade o e ${ }^{9}$, que aparece tanto como objeto do qual se cuida, quanto como de finalidade que se tem em vista. O eu que se tem vista é a velhice, porque, segundo as análises de Foucault (2014a, p. 98; 114), a partir dos estoicos (Sêneca e Epicteto), a velhice aparece como a mais alta forma de cuidado de si, sendo o momento onde nada mais deve importar, a não ser as coisas que estejam no poder do indivíduo, "o momento de sua recompensa estará precisamente na velhice". Já que é na velhice que "o eu finalmente atingiu a si mesmo, reencontrou-se, e em que se tem para consigo uma relação acabada e completa, de domínio e de satisfação ao mesmo tempo" (FOUCAULT, 2014a, p. 98). Logo, o cuidar de si tem como objetivo a preparação para a velhice, já que é, para os estoicos, o momento privilegiado da existência, e mais, afirma Foucault, "o ponto ideal de completude do sujeito" (FOUACULT, 2014a, p. 114).

Para os estoicos, a relação consigo "é sempre considerada como devendo apoiar-se na relação com um mestre, com um diretor, ou, em todo caso, com um outro" (FOUCAULT, 2014c, p. 182). De acordo com Gros (2008, p. 132), o cuidado de si não é uma atividade solitária, que cortaria do mundo aquele que se dedicasse a ele, é mais uma atividade que constitui uma modulação a partir um equilíbrio - uma intensificação da relação social. Tratase de equilibrar "de outro modo esta relação com os outros pelo cuidado de si". Com efeito, o eu de que se preocupa o cuidado de si é uma conquista difícil, visto que, "espontaneamente nós desprezamos este cuidado ético e preferimos o egoísmo". Por isso, a necessidade de chamar o outro, que deve ajudar o indivíduo a cuidar bem de si mesmo (figura do mestre da existência) - o cuidar de si "supõe sempre o acompanhamento de um mais velho e ele se distribui segundo atividades eminentemente sociais: conversações, troca de cartas, ensinamento e aprendizagem em escolas de formações individuais". Nesses moldes, é necessário que o indivíduo desenvolva uma relação com o outro, uma relação de mestre e discípulo, uma relação onde o mestre seja o mediador do aprendizado do discípulo. "O mestre é um operador na reforma do indivíduo como sujeito. É o mediador na relação do indivíduo com sua constituição do sujeito" (FOUCAULT, 2014a, p. 117). Isso acontece porque o indivíduo sozinho não pode ser operador de sua própria transformação. Cabe perguntar, como é possível essa relação do mestre com o discípulo?

\footnotetext{
${ }^{9} \mathrm{O}$ eu apontado por Foucault pode ser encontrado a partir da relação que o indivíduo desenvolve consigo mesmo.
} 
Segundo Foucault (2014a, p. 118), o indivíduo que ainda não começou o percurso pela filosofia, que ainda não desenvolveu a prática de si, tampouco o cuidado consigo, encontra-se no estado de stultitia, ou seja, encontra-se em um estado de "desrazão", em que nada se fixa e nem se deleita. O stultus é aquele "que está à mercê de todos os ventos, aberto ao mundo exterior", aquele que deixa entrar todas as perturbações do mundo exterior. Assim, é necessário que alguém estenda a mão a esse indivíduo e o ajude a sair desse estado, esse alguém é o mestre, ou seja, o outro que ajudará o discípulo a praticar o cuidado de si.

De tal modo, o stultus não se preocupa em não se afetar com as perturbações existentes no mundo exterior, tampouco em fazer a separação entre as representações que lhes são apresentadas. É aquele indivíduo que não se preocupa com o presente ou com o futuro, que não se preocupa em formar uma opinião, pois muda de opinião constantemente, "é alguém que de nada se lembra, que deixa a vida correr, que não tenta reconduzi-la a uma unidade pela rememoração do que merece ser memorizado" (FOUCAULT, 2014a, p. 119), enfim, é aquele que não tem uma meta determinada para sua vida. Nesse sentido, o modo de vida do stultus se opõe ao lema estoico do indivíduo livre que deve viver a cada dia como se estivesse na velhice, que permite tender para uma unidade, onde o que importa é aquilo que está em seu poder. A vontade do stultus não é absoluta, tampouco livre, pois sua vontade sempre depende de algum acontecimento, que pode ser exterior ou interior, não faz distinção, por exemplo, dos prazeres e desejos. De fato, quer várias coisas ao mesmo tempo, "ele quer algo e ao mesmo tempo o lastima. É assim que ele quer a Glória e, ao mesmo tempo, lastima por não levar uma vida tranquila, prazerosa" (FOUCAULT, 2014a, p. 119).

O stultus não quer absolutamente, livremente e sempre, ou seja, não quer o eu, não quer a finalização da técnica de si. Por isso, a necessidade do outro, a necessidade do mestre que o ajude a buscar o eu, que o ajude a sair da stultitia, "fazer com que se possa querer o eu, querer a si mesmo, tender para si como único objeto que se pode querer livremente, absolutamente e sempre" (FOUCAULT, 2014a, p. 120). Por isso, sair da stultitia não pode ser feito pelo próprio indivíduo, de modo solitário, essa saída só é possível por intermédio de outro. Por certo, de um lado, temos um indivíduo que vive à mercê dos ventos, o stultus, e de outro, o que tem o domínio de si, o sapiens, e entre um e outro, temos o mestre, que ajudará o stultus a tornar-se sapiens. "Entre o indivíduo que não quer seu próprio eu, e o que conseguiu chegar a uma relação do domínio e posse de si, de prazer consigo, que é, com efeito, o objetivo da sapientia, é preciso que o outro intervenha" (FOUCAULT, 2014a, p. 120). 
O outro, que intermedia a saída do indivíduo do estado de stultitia para o de sapientia, é o filósofo. Assim, é com o filósofo que o indivíduo encontra os conselhos de como convém agir, como convém conduzir-se e como conduzir os outros. “O filósofo se apresenta [...] como o único capaz de governar os homens, de governar os que governam os homens e de constituir uma prática geral do governo" (FOUCAULT, 2014a, p. 122), governo de si e governo dos outros.

A cultura de si comporta um conjunto de práticas denominadas áskesis. Foucault (2014a, 284) no curso Hermenêutica do sujeito, parte da análise do que não é a áskesis, para então defini-la. Afirma o autor, "ela não é e jamais será fundamentalmente o efeito de uma obediência à lei”, suas técnicas não são desenvolvidas em referências às leis. A áskesis é uma prática da verdade, que liga o indivíduo à verdade. Desse modo, a prática da verdade não se dirige para a uma lei, para uma regra, e sim para o questionamento de como o indivíduo age, "ser como deve, na medida em que não apenas conhece a verdade, mas na medida em que ele diz, prática e exerce?”, em outras palavras, “em que medida o fato de conhecer a verdade, de dizer a verdade, praticar e exercer a verdade, permite ao sujeito não somente agir como deve agir, mas ser como deve ${ }^{10}$ ser e como quer ${ }^{11}$ ser?", enfim, como essa prática de verdade culminará no exercício de liberdade?

A áskesis, para os estoicos, longe de ser uma renúncia severa de si, ou de uma parte de si, é uma constituição de si mesmo, ou seja, é uma relação de si para consigo acabada, autossuficiente, completa e "suscetível de produzir a transfiguração de si que consiste na felicidade que se tem consigo mesmo" (FOUCAULT, 2014a, p. 285-286). Desse modo, a áskesis tem como objetivo proteger o eu e chegar até ele. Segundo Foucault, a áskesis estoica não reduz o indivíduo ao mero aprendizado, ela o equipa e dota. Essa noção de dotar e equipar é denominada de paraskeué - ter a mão, em latim instructio, que pode ser definida como a preparação para os acontecimentos da vida, trata-se de preparar o indivíduo para o futuro, que é constituído de acontecimentos imprevistos. "Trata-se de preparar somente para aquilo com que podemos nos deparar, somente para os acontecimentos que podemos encontrar, não [porém] de maneira a superar os outros [...] trata-se de ser mais forte, ou de não ser mais fraco do que aquilo que pode acontecer" (FOUCAULT, 2014a, p. 285-286). Assim, a paraskeué prepara o indivíduo para lidar com os diversos acontecimentos que lhes possam advir.

\footnotetext{
${ }^{10} \mathrm{O}$ dever pode ser entendido como um termo que impossibilite a prática da liberdade, isso se for pensado como um termo normativo, no entanto, no estoicismo tardio o dever está diretamente relacionado a arte de viver, ou seja, praticar determinados exercícios a fim de se tornar autônomo e, por conseguinte livre.

${ }^{11} \mathrm{O}$ querer está diretamente relacionado a noção de liberdade, pois quando o indivíduo desenvolve o querer e por meio da prática, o mesmo está a praticar a liberdade.
} 
Foucault (2014a, p. 288), esclarece com exemplo de Marco Aurélio, que para ser bom atleta, praticava vários exercícios, ou seja, "que tem paraskeué suficiente [...] é aquele que tem nele arraigado, nele implantado[...] frases efetivamente pronunciadas, frases efetivamente ouvidas ou lidas", frases que ele próprio incrustou no espírito, repetindo-as, em sua memória por exercícios cotidianos, escrevendo-as, escrevendo-as para si em notas como aquelas tomadas. Nas palavras de Foucault:

$\mathrm{Na}$ tradição filosófica inaugurada pelo estoicismo, a áskesis, longe de designar a renúncia a si mesmo, implica a consideração progressiva de si, o domínio de si - um domínio ao qual se chega não renunciando à realidade, mas adquirindo e assimilando sua verdade. (FOUCAULT, 2014c, p. 282).

Segundo Frédéric Gros (2014a, p. 448), essas práticas, essa paraskeué, permitem ao indivíduo aprender a não se deixar perturbar, ou se perturbar o mínimo possível pelos acontecimentos exteriores, tampouco pelas emoções suscitadas no próprio indivíduo. Desse modo, é necessário que o indivíduo se equipe de discursos que possam lhe responder sempre que necessário, esse equipamento é possível a partir de discursos verdadeiros (logoi), de discursos fundados na razão, i.e., "ao mesmo tempo que são razoáveis, são verdadeiros e constituem princípios aceitáveis de comportamento" (FOUCAULT, 2014a, p. 288). Destarte, esses discursos dizem o que é verdadeiro, prescrevem o que é preciso fazer e são persuasivos (no sentido que não acarretam somente a convicção, mas os próprios atos). Foucault afirma que a áskesis tem por objetivo a constituição de uma paraskeué. Explica Foucault:

A áskesis, em razão de seu objetivo final que é a constituição de uma relação de si para consigo plena e independente, tem essencialmente por função, por objetivo primeiro e imediato, a constituição de uma paraskeué - uma preparação, um equipamento (FOUCAULT, 2014a, p. 291).

Preparação que consiste na transformação de discursos verdadeiros em princípios de comportamentos moralmente aceitos, ou seja, é o elemento que possibilita a transformação do logos no êthos - modo ser. Assim, a áskesis pode ser definida como "o conjunto, a sucessão regrada, calculada de procedimentos que são aptos para que o indivíduo possa formar, fixar definitivamente, reativar periodicamente e reforçar quando necessário, a paraskeué" (FOUCAULT, 2014a, p. 291), possibilitando a esse indivíduo o dizer verdadeiro ${ }^{12}$. Assim, a paraskeue, permite o domínio de si diante dos acontecimentos. Esses discursos podem ser

\footnotetext{
${ }^{12}$ A parrésia aparece no pensamento de Foucault com o curso Hermenêutica do sujeito (1982), "faz sua irrupção no contexto do estudo das práticas do cuidado de si mesmo, para qualificar o discurso que dirige o mestre ao discípulo" (CASTRO, 2015, p. 144). Já nos cursos O governo de si e dos outros e a Coragem da verdade, essa não aparece com um cunho mais amplo, numa relação mais horizontal de um discípulo para outro. Em linha gerais, dizer verdadeiro significa falar francamente, dizer tudo.
} 
formados a partir de três questões, a saber: a questão da natureza, o modo de existência desses discursos e as questões técnicas sobre o modo de apropriação.

Ademais, o cuidar de si se faz quando o indivíduo: em primeiro lugar, busca conhecer o mundo, as causas de prodígios, as leis da vida e da morte, enfim, quando busca entender a natureza, para se preparar para os possíveis acontecimentos; em segundo lugar, é preciso que o indivíduo conheça esses acontecimentos e saiba quando recorrer a eles, quando apelar para os discursos verdadeiros; e em terceiro, a necessidade de desenvolver a ascese, o método de apropriação dessas práticas, ou seja, a importância da escuta (na relação com o outro), o retorno sobre si (memorização), e por fim, fornecer ao indivíduo, uma verdade que ele não sabia que existia e que não residia nele, "trata-se de fazer dessa verdade aprendida, memorizada, progressivamente aplicada, um quase-sujeito que reina soberanamente em nós" (GROS, 2014a, p. 451).

De tal modo, a áskesis estoica, de um lado, permite adquirir os discursos verdadeiros a fim de estabelecer uma relação adequada, plena, consigo, e de outro, permite fazer de si mesmo o indivíduo desse discurso, ou seja, o indivíduo que diz a verdade. Essa áskesis busca encontrar a si mesmo "como fim e objeto de uma técnica de vida, de uma arte de viver. Tratase de encontrar a si mesmo em um movimento cujo momento essencial [...] é subjetivação de um discurso verdadeiro em uma prática e em um exercício de si sobre si” (FOUCAULT, 2014a, p. 296-297). Por certo, a áskesis faz com que o indivíduo tome aquilo que ele ouve, que sabe, os discursos que ele reconhece como seus, enfim, faça sua a verdade ouvida e tornese sujeito do enunciado verdadeiro.

Foucault (2014a, p. 296-297), inicialmente, examina o procedimento da escuta como prática da áskesis. A escuta é considerada o primeiro passo, o primeiro procedimento da subjetivação do discurso verdadeiro, pois é a partir dela que é possível o indivíduo reconhecer o logos, ou seja a verdade existente nesses enunciados: “A escuta será o primeiro momento desse procedimento pelo qual a verdade ouvida, a verdade escutada e recolhida como se deve, irá de algum modo entranhar-se no sujeito, incrustar-se nele e começar a tornar-se suus e a constituir assim a matriz do êthos" - a passagem da alétheia ao êthos, ou seja, do discurso de verdade ao modo de ser, à conduta.

Grosso modo, é necessário que o indivíduo saiba escutar, pois nem tudo que for escutado deve ser tomado como verdade e nem passado da verdade ao êthos. O indivíduo que domina a si mesmo sabe escutar e quando convém escutar, porque escuta por meio de uma arte, de uma técnica. No entanto, essa arte não pode ser entendida como arte no sentido 
estrito, aqui arte deve ser tomada como uma experiência, uma maneira de familiarizar-se com as exigências da escuta. Trata-se, em suma, de uma vivência "nessa prática refletida, nessa prática aplicada da escuta, de purificar a escuta lógica" (FOUCAULT, 2014a, p. 303). Segundo Foucault, essa prática refletida, essa purificação da escuta na prática de si, acontece de três modos: primeiro, pelo silêncio, ou seja, a necessidade de que, por um determinado tempo, o indivíduo apenas escute o que o mestre tem a falar; em segundo, uma atitude ativa, uma atitude física, onde o indivíduo deve acolher sem perturbação aquilo que lhe foi proferido, com a máxima escuta; em terceiro, é necessário um compromisso, uma manifestação da vontade da parte do indivíduo. Desse modo, o indivíduo que busca uma vida bela, deve agir com liberdade, com autonomia, deve buscar uma certa forma, em outras palavras, é o desenvolvimento de um estilo do viver. Grosso modo, essa vida bela pode ser alcançada por meio do domínio de dois exercícios ascéticos, a saber: a meletân e a gymnázein.

Gymnázein é o treino em situação real, ou seja, o indivíduo deve exercitar-se, treinarse, enfim praticar para si mesmo. Diante disso, Foucault elenca dois tipos de gymnázein, a saber: o regime das abstinências e o das provas. Interessa aos estoicos os regimes de abstinências ligados à alma e ao corpo, e os conjugados (corpo e alma), de modo que o corpo não seja negligenciado, uma vez que mesmo que o indivíduo busque a filosofia, é necessário que exercite o corpo, visto que o corpo é considerado um instrumento cujas virtudes são úteis às ações da vida.

Os exercícios da alma e do corpo devem ter como objetivos a coragem (andreía) e a moderação de si mesmo (sophrosýne). Com a coragem, o indivíduo deve ter em vista a resistência aos acontecimentos exteriores, "a capacidade de suportá-los sem sofrer, sem sucumbir, sem se deixar vencer por eles" (FOUCAULT, 2014a, p. 383). Em seguida, com a sophrosýne, deve permitir, medir, regrar e dominar todos movimentos interiores, de si mesmo. Então, de um lado, temos exercícios que lidam com os acontecimentos exteriores, e de outro, exercícios que lidam com o interior do indivíduo, com a dominação de si mesmo. Esses exercícios acontecem ou são possíveis, por meio da abstinência, isto é, resistência à fome, à sede, ao frio, ao excesso de calor.

Segundo Foucault (2014a, p. 386), o que está em questão, nesses exercícios de resistências, não é o corpo atlético, físico, e sim o corpo de paciência, o corpo de resistência, o corpo de abstinências. O regime de abstinência não tem o objetivo de levar o indivíduo a se abster de todas as coisas, mas levá-lo a praticar um exercício recorrente que permita dar forma à vida, permita ao indivíduo ter em face dele mesmo e dos acontecimentos a atitude que 
convém: "Suficientemente desprendida para suportar o infortúnio quando ele ocorre". Desse modo, temos exercícios de abstinências com o objetivo de formar um estilo de vida e não para regrar a vida mediante interdições e proibições.

Em seguida, Foucault (2014a, 387) analisa o regime das provas ${ }^{13}$, distinguindo-as da abstinência por meio de uma interrogação de si sobre si, isto é, o indivíduo busca saber se deve fazer determinada coisa e fazê-la até o fim de modo esclarecido e consciente. Esse regime das provas tem uma estreita relação com a verdade, pois é a partir da relação de si sobre si que será possível ao indivíduo se ver como sujeito de verdade.

A prova deve estar relacionada a dois tipos de exercícios, primeiro a prova enquanto interrogação de si, a qual permite medir em que ponto o indivíduo está em relação a aquilo que era, e qual o progresso já feito, em relação ao que se deve chegar. O segundo é a prova como exercício que envolve o ambiente no qual o indivíduo vive e o pensamento: "quanto estamos em uma situação na qual corremos o risco de ser compelidos pela paixão, devemos enfrentá-la, abdicar certamente de tudo o que poderia nos compelir e fazer com que [...] nos refreemos" (FOUCAULT, 2014a, p. 389).

Por meletân temos meditation, em latim, que se trata de um exercício real do pensamento, e não de enclausuramento do pensamento, isto é, uma espécie de preparação concentrada em si mesma, que ao mesmo tempo medita e prepara o indivíduo para falar livremente. Aqui temos meletân como "um trabalho que o pensamento exerce sobre si mesmo, um trabalho do pensamento, mas que tem essencialmente por função preparar o indivíduo para aquilo que ele em breve deverá realizar" (FOUCAULT, 2014a, p. 382).

A meletân consiste em fazer o exercício de apropriação do pensamento, no caso do discípulo, fazer uma retomada periódica de tudo o que aprendeu com o mestre. Por exemplo, a meditação sobre a morte, é necessário pensar não tanto na morte, mas no caminho até ela, ou seja, pôr-se no lugar de alguém que está findando a vida, de alguém que está doente, por exemplo. Trata-se do jogo que não é do indivíduo com seu próprio pensamento, mas o pensamento sobre o próprio indivíduo: "É o exercício pelo qual o sujeito se põe, pelo pensamento, em uma determinada situação" (FOUCAULT, 2014a, p. 319-320).

\footnotetext{
${ }^{13}$ Foucault (2014a, p. 387) explica que um exemplo da prova, enquanto interrogação sobre si, é o que "diz Epicteto: o que se deve fazer para lutar contra a cólera? Pois bem, deve-se comprometer-se consigo mesmo a não se encolerizar durante. Depois, faz-se um pacto consigo mesmo para dois dias, em seguida para quatro dias, e finalmente, feito o pacto consigo mesmo para não se encolerizar durante trinta dias, e tendo-se efetivamente conseguido cumpri-lo, então é o momento de oferecer um sacrifício aos deuses".
} 
A meditação para os estoicos parte do pressuposto de que a necessidade "de cuidar de si mesmo, de poder e dever cuidar de si mesmo" (FOUCAULT, 2014a, p. 410) que se relaciona com o fato de o indivíduo dispor de outra capacidade de entendimento, que não a do período clássico - que buscava por meio da memória seguir os "passos do mestre". Com efeito, no período estoico, a meditação ocorre por meio da razão. Segundo Foucault, o mestre pode até dizer como o indivíduo deve agir, no entanto, se quiser saber como agir, pode por meio da razão, retomando o que aprendeu e de modo livre realizar o cuidado de si. Assim, "cuidar de si mesmo não é servir-se das faculdades que se tem, mas servir-se delas somente quando determinamos esse uso recorrendo" à faculdade que determina se convém ou não usar, ou seja, a razão.

Segundo Foucault (2014a, p. 412), a meditação tem uma relação com o divino, que não é a encontrada no período clássico - o divino descoberto no próprio eu, na alma. A relação que o indivíduo tem com o divino, na prática da meditação estoica, está relacionada ao ocupar-se consigo mesmo, ao modo como o indivíduo reflete sobre a natureza de seu próprio governo, pois é no ocupar-se consigo que se reflete o divino. Com efeito, o indivíduo reflete seu governo, o governo de si mesmo e o governo que exerce sobre o outro, para saber se é digno de si. Esclarece Foucault:

Repousar em si mesmo, estar, portanto, em um estado de ataraxia; refletir sobre a natureza de seu próprio governo, isto é, saber com sua razão, a razão de Deus, se exercerá sobre as coisas; enfim entreter-se com pensamentos dignos de si, entreter-se consigo mesmo: estas são [...] as particularidades que caracterizam a posição do sábio, uma vez que tenha precisamente alcançado a sabedoria (FOUCAULT, 2014a, p. 412).

Com efeito, o indivíduo que medita, na relação com o divino, desenvolve características que são próprias do sábio, isto é, o indivíduo que busca o cuida de si desenvolve uma relação com o divino a qual reflete sobre seu governo, sobre o governo que exerce sobre o outro, o modo que se entretém com os próprios pensamentos. São esses os objetivos da meletân, a saber: meditar, estar preparado para os diferentes e possíveis acontecimentos, e as possíveis coisas que os aflija.

Assim, a meditação como prova é o exercício do sujeito com ele mesmo e com a verdade, o qual se questiona sobre sua conduta e sobre seu pensamento como verdade de indivíduo ético, desse modo, Foucault traz como exemplo de práticas que desenvolvam a meditação: prática do exercício da morte e o exame de consciência. De tal modo, o exercício da morte está diretamente ligado à premeditação dos males (praemeditatio malorum), onde o exercício da prática de si prepara o indivíduo para não se deixar preocupar com o porvir, com 
aquilo que está no futuro, ou seja, com aquilo que não tem certeza se acontecerá. Desse modo, é necessário que o indivíduo não seja stultus, se preocupando com aquilo que ainda não aconteceu, e passe a se preocupar consigo mesmo.

Pensar sobre o porvir e sobre a morte são coisas diferentes para os estoicos. No primeiro caso, o indivíduo que se ocupa consigo não se ocupa com o porvir, não se preocupa com o lhe possa acontecer futuramente, como já mencionado. No segundo caso, existe a necessidade de o indivíduo tomar consciência da morte, pois assim poderá viver como convém, ou seja, viver cada dia como se fosse o último. A importância dada à meditação sobre a morte ocorre no processo de o indivíduo perceber a si mesmo de duas maneiras. De um lado, o indivíduo terá uma visão do alto (para o elemento divino) sobre sua vida presente, revelando-se o que está fazendo, o modo como está agindo. De outro lado, um olhar de retrospecção sobre o conjunto da vida. Segundo Foucault (2014a, p, 431), a morte não se relaciona com o porvir, pois ela é um meio para adotar sobre a vida um olhar que "opera um corte permitindo apreender o valor do presente". Com efeito, temos como ponto central, uma valorização do passado e um julgamento do presente, ou seja, quando o indivíduo se dá conta da morte e passa a praticar exercícios que o possibilite se preparar e se afetar o mínimo possível com os acontecimentos, desse modo, essa preparação permite ao indivíduo pensar sobre si mesmo enquanto está vivo.

Passemos ao exame de consciência, o qual permitirá a purificação do pensamento antes do sono por exemplo, e tem como objetivo propiciar a disponibilidade de discursos verdadeiros que o indivíduo se permita conduzir. Por um lado, o exame de consciência é reativação das regras feitas durante o dia e que ocorre sempre no espírito, e por outro, é considerado prova, que por meio da recordação do dia e das regras, possibilita ao indivíduo medir em que ponto está: se tem “ainda um grande esforço a fazer", se está longe da meta e se é capaz de traduzir em ações os princípios de verdade que se dispõe na ordem do conhecimento.

Por conseguinte, o indivíduo que busca, a partir desse exercício, se preparar para levar a vida como uma prova, tem como objetivo elaborar discursos verdadeiros para sua conduta, que permite-lhe se preparar para cuidar de si, se equipar-se para uma série de acontecimentos imprevistos, em relação "aos quais porém serão praticados alguns exercícios que os atualizam com uma necessidade inevitável [...] a fim de reduzi-los estritamente ao mínimo de sua existência" (FOUCAULT, 2014a, p. 436), i.e., deixar de lado tudo que for imaginação e que de algum modo o atinja, o desvie do cuidado de si, e se preparar sempre e continuamente 
para viver a existência como uma prova de si. Nesse interim, os exercícios ascéticos permitem ao indivíduo constituir-se como verdadeiro sujeito da ação reta. Nessa fase - constituição de si como sujeito da ação reta, já é a prática da liberdade?

Foucault (2014a, 436) afirma que todos esses exercícios possibilitam o bíos (a vida) sair da condição de correlato de uma tekhne, para a condição de uma forma de prova de si. Por isso, analisamos as três maneiras ou formas de exercícios do pensamento, de exercício de si sobre si mesmo, que possibilitaram o exercício da filosofia e a prática, a saber: a meditação estoica, que opera a partir daquilo que se pensa, ou seja, a prova de si mesmo, a partir do modo como pensa e age, tendo como objetivo a transformação de si como "sujeito ético da verdade"; reflexão do pensamento sobre si mesmo, isto é, o método, que permite fixar a certeza capaz de servir como critério de verdade para a constituição do conhecimento; a memória, que propicia o acesso à verdade, na forma do reconhecimento, nessa forma, que abre para uma verdade da qual se lembra", o indivíduo encontra-se modificado, pois nessa prática consegue fazer um retorno a si mesmo, ao seu ser próprio.

Importante ressaltar que Foucault (1995, p. 75) não pretende em seus escritos fazer uma análise dos costumes, nem tampouco uma história dos costumes, importa para o filósofo francês, entender a maneira como o prazer, o desejo, os comportamentos sexuais foram problematizados ${ }^{14}$ e pensados na antiguidade clássica e no estoicismo tardio em relação a uma arte de viver. Assim, afirma Foucault que "o que tenta fazer é a história das relações que o pensamento mantém com a verdade; a história do pensamento enquanto pensamento da verdade" (FOUCAULT, 1995, p. 76). Pode-se notar como os temas estoicos da relação consigo, com o outro e com a verdade, nos encaminham para uma reflexão sobre o papel da liberdade, ou seja, como a partir desses exercícios é possível problematizar a liberdade como uma atitude do indivíduo, como um modo de vida, como um êthos.

\section{Considerações Finais}

Tendo em vista as problematizações e análises feitas a partir da prática de liberdade, no pensamento de Foucault, temos no estoicismo tardio um sujeito livre constituído no processo de subjetivação, ou seja, o indivíduo que se constitui e desenvolve o cuidar de si. À vista disso, entendemos que o cuidado de si se constitui a partir de um processo de estetização, ou seja, a partir de um êthos que culminará no exercício de liberdade, de uma

14 "Problematização não quer dizer representação de um objeto preexistente, nem criação pelo discurso de um objeto que não existe. É o conjunto das práticas discursivas ou não discursivas que faz alguma coisa entrar no jogo do verdadeiro e do falso e à constitui como objeto para o pensamento (seja sob a forma de reflexão moral, do conhecimento científico, na análise política, etc.) "(FOUCAULT, 1983, p. 76). 
liberdade individual ${ }^{15}$ - de uma conduta individual, que funciona por meio de uma escolha do indivíduo - pensada como ética. Por isso, o problema ético analisado, consiste no modo como o indivíduo desenvolve a prática de si, por meio de exercícios regulares, buscando transformar seu ser, buscando não ser escravo de si mesmo, exercendo soberania sobre os desejos e prazeres, e sobre os possíveis acontecimentos. Assim, os exercícios da prática da liberdade farão com que o indivíduo se conduza de forma adequada em relação a si mesmo e aos outros.

Desse modo, temos um indivíduo que se constitui e desenvolve o cuidado de si, a partir de um conjunto de práticas de existência construídas historicamente, promovendo, segundo sua vontade, uma forma ou estilo de vida que culminará em uma arte de viver - vida bela, a qual é modelada por algumas formas de estetizações. Estetizações essas, que ocorrem pela inciativa de uma "transformação de si sobre si", ou seja, o indivíduo ao se transformar, ao se debruçar sobre si mesmo, consegue desenvolver novas formas de subjetivação.

Nesse interim, é diante da possibilidade de viver uma vida bela que o indivíduo vislumbra um viver diferente, pautado no domínio de si. E como apontado no decorrer do texto, o indivíduo domina a si mesmo quando se torna livre dos desejos e prazeres. Com efeito, o tornar-se livre é possível a partir do cuidado de si, que, por meio das técnicas desenvolvidas na relação com o mestre, fará com que esse indivíduo se aproxime cada vez mais do estado de liberdade e de racionalidade. Por isso, o problema ético analisado, ou a prática da liberdade, consiste no modo como o indivíduo desenvolve a prática de si, por meio de exercícios regulares, buscando transformar seu ser, buscando não ser escravo de si mesmo, exercendo soberania sobre os desejos e prazeres, e sobre os possíveis acontecimentos, se conduzindo de forma adequada em relação a si mesmo e aos outros.

É no desenvolvimento da relação consigo e transformação de si, que o indivíduo encontra como alternativa um modo de resistência, a saber: a partir o cuidado e si, que o indivíduo resiste aos prazeres e desejos. Desse modo, o êthos, o modo de vida desenvolvido, no estoicismo tardio, consiste num modo de liberdade ética pautado no modo como indivíduo conduz sua vida, seus desejos e prazeres, pois, quando o indivíduo passa a cuidar de si, diminui as chances de ser escravo de si mesmo, de se abalar de modo exacerbado pelos acontecimentos que são possíveis de acometê-los.

\footnotetext{
${ }^{15}$ Liberdade individual, pois no estoicismo tardio está em vigor a noção de subjetividade que para Foucault significa uma "reflexividade que se poderia chamar de prática: uma maneira de se relacionar consigo mesmo para se construir, para se elaborar", e não uma individualização com o sentido de um egoísmo ou solidão do indivíduo" (GROS, 2008, p. 128).
} 
Destarte, a análise da prática de liberdade ética nos permite entender como é possível ser livre e conceder autonomia numa possibilidade de resistência a um tipo de subjetivação tematizada que se fez presente, na modernidade, como produto do biopoder, por exemplo, bem como as formas de limitações impostas pelo exercício do poder. No viés do poder moderno (sociedade moderna), o modo de vida defendido por Foucault, enquanto crítica consiste num cuidado de si, mas não uma rememoração do modo de vida do estoicismo tardio, mas a busca de novos modos de ação, que evoca uma luta agonística e incessante travada no próprio indivíduo, e impulsiona o indivíduo a tomar distanciamento de identidades pré-constituídas, de limitações pré-estabelecidas. De tal modo, é a partir da relação consigo que ocorre no indivíduo a transformação de si e do mundo, visto que não há transformação do mundo sem transformação de si, isto é, uma luta política que consiste numa ação sobre ação, enfim, na relação de forças do eu em face dos outros.

\section{REFERÊNCIAS BIBLIOGRÁFICAS}

CANDIOTTO, Cesar. A Governamentalidade política no pensamento de Foucault. Filosofia Unisinos. 11. 33-43, jan/abr. 2010.

CASTRO, Edgardo. Vocabulário de Foucault: um percurso pelos seus temas, conceitos e autores. Trad. Ingrid Müller Xavier. 2. Ed. Belo Horizonte: Autêntica, 2016.

RABINOW, Paul; DREYFUS, Hubert. Michel Foucault Uma trajetória Filosófica: Para além do estruturalismo e da hermenêutica. Trad. Sob a direção de Vera Porto Carrero. Forense Universitária. São Paulo: Editora Taurus, 1995. p.: 271-278.

FOUCAULT, Michel. História da Sexualidade II: O uso dos prazeres. Trad. Maria Thereza da Costa Albuquerque. Rio de Janeiro: editora Graal, 1984. V. 2.

FOUCAULT, Michel. A hermenêutica do sujeito: curso dado no Collège de France. Edição: Frédéric Gros. Trad. Marcio Alves Fonseca, Salma Tannus. 3. Ed. São Paulo: editora Martins Fontes, 2014a.

FOUCAULT, Michel. Ditos e escritos: Ética, sexualidade, política. Organização de textos Manoel Barros da Motta. Trad. Elisa Monteiro, Inês Autran Dourado Barbosa. 3. Ed. Rio de Janeiro: Forense Universitária, 2014b. V. 5.

FOUCAULT, Michel. Ditos e escritos: Genealogia da ética, subjetividade e sexualidade. Organização de textos Manoel Barros da Motta. Trad. Abner Chiquieri. Rio de Janeiro: Forense Universitária, 2014c. V. 9.

FOUCAULT, Michel. Ditos e escritos: Estratégia, poder-saber. Organização de textos Manoel Barros Motta. Trad. Vera Lucia Avellar Ribeiro. 2. Ed. Rio de Janeiro: Forense 
Universitária, 2015. V. 4.

FOUCAULT, Michel. O dossier: últimas entrevistas. São Paulo: Editora Taurus, 1999.

FOUCAULT, Michel. Subjetividade e verdade: curso dado no Collège de France. Edição: Frédéric Gros. Trad. Rosemary Costhek Abílio. São Paulo: editora Martins Fontes, 2016.

GROS, Frédéric. Desobedecer. Trad. Célia Euvaldo. São Paulo: Ubu Editora, 2018.

GROS, Frédéric. Situação do curso: Subjetividade e verdade. Trad. Rosemary Costhek Abílio. São Paulo: editora Martins Fontes, 2016.

GUTTING, Gary. (Org.) Foucault. Trad. André Oídes. São Paulo: Ideias \& Letras. 2016. p.: 189-230.

SENELLERT, Michel. Situação do curso: Governo dos vivos. Trad. Eduardo Brandão. São Paulo: Editora Martins Fontes, 2014.

SENELLERT, Michel. Situação do curso: Segurança, território e população. Trad. Eduardo Brandão. São Paulo: Editora Martins Fontes, 2008.

REVEL, Judith. Foucault Conceitos Essenciais. Trad. Sob a direção de Carlos Piovezani Filho e Nilton Milanez. São Carlos: Editora Claraluz, 2005.

Artigo recebido em: 02/06/20

Artigo aprovado em: 05/10/20 